\title{
Novas percepções sobre a loucura e os primeiros passos da psiquiatria na Espanha
}

\section{New insights on madness and the early years of psychiatry in Spain}

\author{
Ricardo Cabral de Freitas \\ Doutorando do Programa de Pós-graduação em História das Ciências e da Saúde/Casa de Oswaldo Cruz/Fiocruz. \\ rcabral.freitas@gmail.com
}

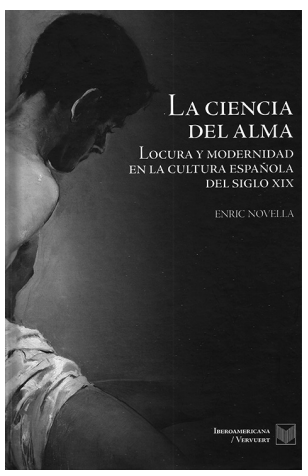

NOVELLA, Enric. La ciencia del alma: locura y modernidad en la cultura española del siglo XIX. Madrid: Iberoamericana; Frankfurt: Vervuert. 2013. $224 p$.
$\mathrm{D}^{\mathrm{c}}$ e autoria de Enric Novella, médico, filósofo e pesquisador da Universidade de Luxemburgo, a obra procura dar conta dos primeiros passos da psiquiatria na Espanha. Tomando como ponto de partida a mudança de atitude da opinião pública do país em relação à loucura, ocorrida na esteira da ascensão da ordem liberal nos anos 1830 e 1840, Novella analisa a presença crescente de discursos sobre a medicina mental em vários ramos da cultura letrada espanhola e o modo como, na segunda metade do século, esses mesmos discursos se tornaram parte de uma ordem moral de teor progressivamente autoritário e universalizante.

O livro se divide em quatro capítulos, e, ao fim, o leitor pode contar com um índice onomástico bastante útil que dá conta da variedade dos temas abordados no texto. O primeiro capítulo, "Ciudadanos y locos", é dedicado a uma breve análise da cultura letrada espanhola desde o final do século XVIII, demonstrando a influência do romantismo sobre a mudança de percepção da loucura em curso desde então. No segundo, "Los paisajes del alma", Novella explora a ascensão do liberalismo espanhol para mostrar como a noção de individualidade que se afirma a partir da década de 1830 contribui para disseminar de modo definitivo o interesse pela loucura e pelas ciências da mente no país. No terceiro, "La medicina del espíritu", a ênfase recai sobre os debates médicos da época e a presença marcante de questões relativas à alma e às paixões, como forma de tentar desvendar seus efeitos sobre o físico e o moral humanos. O quarto e último capítulo, "El malestar en la cultura", aponta como a assimilação dessas noções de enfermidade, loucura e desordem pelo discurso médico espanhol se transmutam num diagnóstico pessimista da civilização, combatido através de um discurso marcadamente moralizante e repressor. 
A narrativa se desenvolve a partir de um estreito diálogo com as transformações sociopolíticas que marcaram a vida intelectual do país na primeira metade do Oitocentos, sendo constantes as referências a romances, relatos de escritores da época e debates na imprensa médica que evidenciam o crescente interesse do público letrado espanhol pelo psiquismo. Segundo o autor, o louco era cada vez menos representado como um indivíduo completamente alheio à realidade e destituído de humanidade, e passava a ser visto como um indivíduo enfermo que necessitava de ajuda. Sobre esse aspecto, é sintomático o horror dos letrados espanhóis ao constatar o péssimo tratamento dispensado aos loucos do país, como descrito no primeiro capítulo.

De certo modo, podemos dizer que o processo explorado por Novella é uma expressão mais localizada das reformulações das concepções sobre a loucura ocorridas no século XVIII, como apontadas por Foucault (2012) em História da loucura na idade clássica. Ao deixar de ser vista como um estado irreversível de completo descolamento da realidade, a loucura passa a ser entendida como uma desordem das ideias, passível de reversão mediante intervenção externa. Apontada pela historiografia da psiquiatria como condição fundamental para o alienismo, essa transformação, em outras palavras, marca o fim do entendimento da mente como um domínio inacessível e abre espaço para sua apropriação pelo discurso médico, num processo que tem como um de seus principais marcos o tratamento moral pineliano na França da virada do século XVIII para o XIX.

No contexto espanhol, essa transformação só tomaria contornos sociais e institucionais mais definitivos nas décadas de 1830 e 1840. Para o autor, a morte de Fernando VII em setembro de 1833 põe fim a uma longa crise política no país e marca o sepultamento definitivo do antigo regime espanhol, abrindo caminho para o assentamento das bases de um regime de caráter liberal:

Assim, os anos e as décadas seguintes certificaram a progressão de uma série de fenômenos tão significativos da transição ao mundo contemporâneo, como a substituição do Estado patrimonial do absolutismo por uma monarquia constitucional sustentada em fórmulas de soberania compartilhada; a emergência de uma incipiente economia capitalista e a implantação de um modelo classista de organização social, baseado na hegemonia normativa dos princípios de liberdade, igualdade e, sobretudo, propriedade (p.78).

Para o autor, é somente a partir dessa entrada "tardia" da Espanha na modernidade que se forma uma conjuntura favorável à difusão de novas concepções sobre a relação mente/ corpo no país, caracterizada pela reunião de quatro elementos fundamentais: (a) a paulatina extensão dos ideais democráticos, filantrópicos e emancipadores articulados na opinião pública liberal; (b) crescente projeção e problematização cultural de uma subjetividade dividida entre o cultivo de si mesma e sua constituição como o objeto de um conjunto de novas doutrinas e disciplinas científicas; (c) circulação dos pressupostos conceituais, ideológicos e culturais das novas ciências da mente; (d) ampla percepção de uma crise permanente na cultura moderna que exigia uma profunda regeneração moral e uma ilimitada intervenção dos médicos na regulação dos assuntos humanos (p.42).

Em parte, o interesse do público letrado espanhol pela medicina mental está relacionada à afirmação da sensibilidade romântica naquele ambiente intelectual, expressa num modelo 
de individualidade ligado às ideias liberais e marcado por uma preocupação maior com a "verdade interior" e a "experiência individual". A afirmação desse interesse pelo que Novella chama de "esfera moral" foi sacramentada na aprovação pela rainha Isabel II do "Plano General de Estudios" em 1845. O plano, proposto pelo ministro Pedro José Pidal, criou a disciplina "Princípios de psicologia, ideologia y lógica", que marca a entrada definitiva dos debates psicológicos no ensino secundário espanhol, em detrimento da religião e da moral.

Nesse amplo contexto, o autor identifica uma circulação alargada de teorias médicas que eram debatidas com força em outros círculos letrados europeus desde o fim do século XVIII - sobretudo na França - a exemplo da frenologia e do magnetismo. Destaca-se também a proliferação dos manuais e obras de inspiração espiritualista, representados por Elementos de psicologia (1848), de Pedro Felipe Monlau, que se tornou o livro de psicologia mais recomendado durante os governos isabelinos.

Segundo Novella, esse estado de coisas na cultura letrada espanhola desse período marca a aceitação definitiva do projeto ilustrado de reconhecimento da consciência. Assim, o saber médico apresenta-se cada vez mais como um saber de caráter antropológico, o que leva a uma ordenação da moral - pelo menos no plano discursivo - direcionada pela ciência. Um sintoma desse novo cenário é a entrada em território espanhol dos postulados da science de l'homme francesa, que passa a impregnar vários escritos médicos espanhóis da primeira metade do Oitocentos. A abordagem holística sobre o homem, característica fundamental desse discurso, contribui para o teor fortemente pedagógico dessas obras, fundamentadas na noção de que só o profundo conhecimento da natureza humana poderia gerar uma sociedade justa.

Ao final, Novella (p.165) procura mostrar como, ao longo do século, essa retórica médica renovada se transmuta no que chama de "moralização da medicina, em vez de medicalização da moral". Diante da percepção de uma profunda crise social, na qual a civilização era apontada pelo discurso conservador espanhol como um "um manancial de excitações cerebrais" (p.165), a medicina se apresenta como instância capaz de intervir em prol da manutenção da coesão social. Por meio dos acalorados debates em torno dos efeitos da imaginação, da vontade e das paixões sobre a condição física e moral dos indivíduos, Novella demonstra o progressivo avanço médico sobre os processos de definição de padrões de conduta moral aceitáveis, de teor progressivamente universalizante.

O epílogo foi reservado para um esboço dos caminhos tomados pela psiquiatria espanhola a partir da segunda metade do XIX. Chama a atenção o fato de que só nos últimos parágrafos, Novella (p.177) dá pistas sobre as resistências enfrentadas pelo nascente discurso psiquiátrico espanhol, citando um único caso no qual médicos foram presos por ordem do governador civil de Valência após terem internado uma mulher pertencente a uma família abastada da cidade, sob o diagnóstico de "monomanía razonante". Sem dúvida, a presença de controvérsias dessa natureza ao longo do livro teria sido de grande valia para dar a devida dimensão do alcance das transformações discursivas tratadas pelo autor.

Por outro lado, o recurso à produção literária de época - além das teses médicas - foi fundamental para dimensionar o alcance que o vocabulário do psiquismo teve em setores variados da elite letrada espanhola no período. Novella é bem-sucedido ao mostrar que a mudança de postura em relação à loucura foi um processo amplo, que apesar de dialogar intensamente com a esfera médica, nunca se limitou a ela. 
Por fim, apesar da ênfase nas décadas centrais no século XIX, o autor mostrou preocupação em expor as conexões da nascente psiquiatria espanhola com o contexto iluminista das últimas décadas do século XVIII. Em certa medida, as referências à science de l'homme francesa localizam o início da psiquiatria na Espanha na esteira das concepções sobre a natureza humana e a relação corpo/alma forjadas nos debates médicos franceses a partir da segunda metade do Setecentos. São esses debates que, ao conceber o homem a partir da noção de "sensibilidade", turvam os limites entre os domínios da alma e do corpo, rompendo com a intocabilidade da alma, tal como foi definida pela tradição cartesiana.

Ao analisar o alienismo a partir dessa perspectiva Novella oferece uma abordagem mais abrangente, que não se contenta em tomar o tratamento moral pineliano como ponto partida para o nascimento da psiquiatria. Além disso, ao trazer essas questões para um contexto ibérico, contribui para a compreensão de assunto ainda pouco explorado.

\section{REFERÊNCIAS}

FOUCAULT, Michel.

História da loucura na idade clássica. São Paulo:

Perspectiva. 2012. 